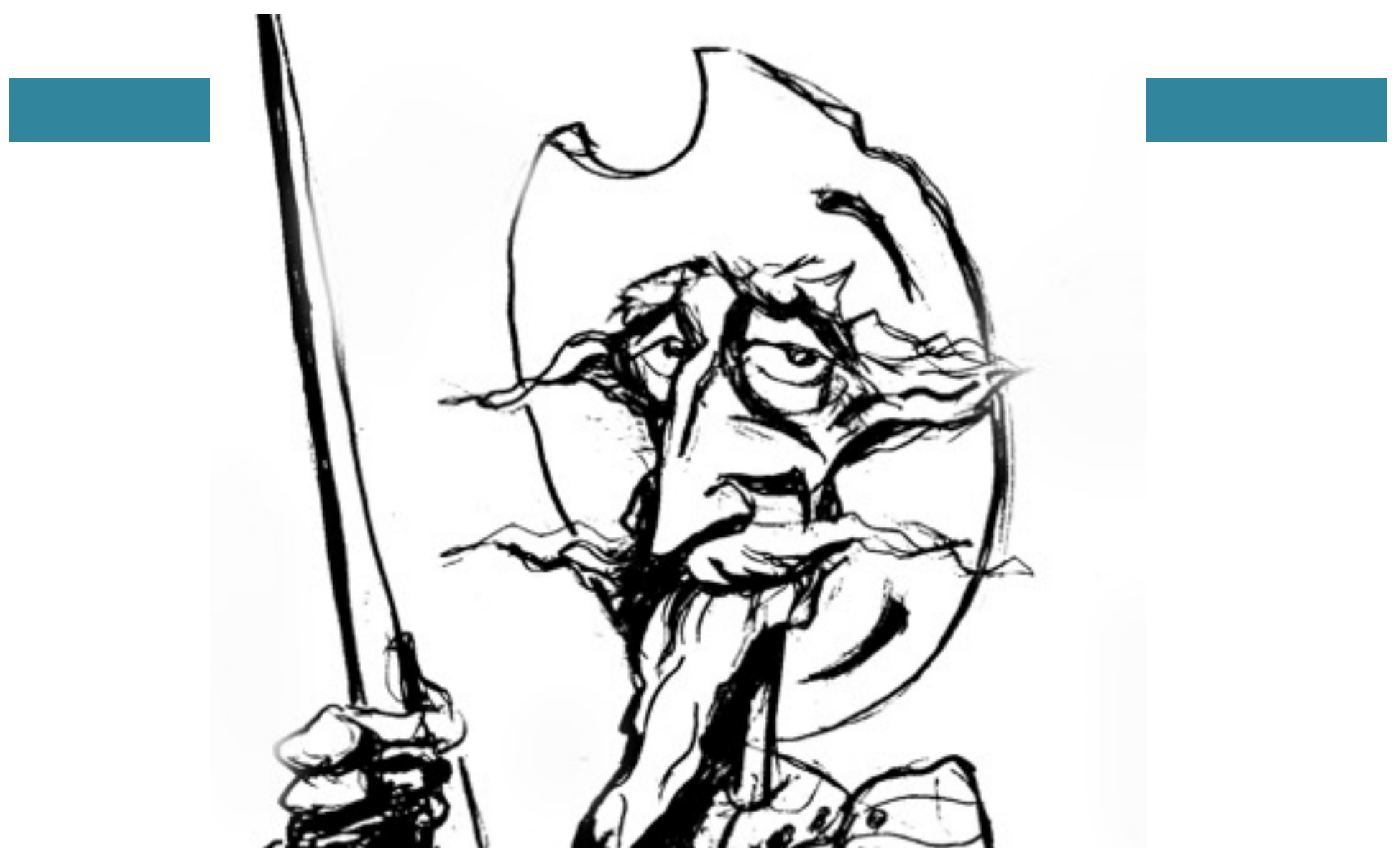

Entre el Estado y la utopía, entre la nación y la otredad: un diálogo con el joven Garavaglia de los años sesenta

[Juan Pro y María Sierra] 


\section{Entre el Estado y la utopía, entre la nación y la otredad: un diálogo con el joven Garavaglia de los años sesenta}

\section{Between State and Utopia, between Nation and Otherness: a dialogue with the young Garavaglia of the sixties}

JUAN PRO

MARÍA SIERRA

\begin{abstract}
Resumen
A través del recuerdo de experiencias personales y de un diálogo con el libro de memorias de Juan Carlos Garavaglia, Una juventud en los años sesenta, los autores reflexionan sobre los problemas que lo preocuparon, como historiador y como hombre comprometido con la realidad social de su tiempo. El diálogo se ensaya en torno a los temas de investigación propios de los autores de este texto: la utopía, entendida como impulso político hacia el futuro antes que como un específico género literario; y la otredad de un pueblo históricamente castigado por la exclusión, como es el gitano; a los que se suma la referencia a una visión no convencional del Estado. Destacan el pluralismo cultural y la tolerancia intelectual de Juan Carlos; proponiendo saltar las mismas barreras contra las que él había batallado: aquellas interpuestas por los "nacionalismos", las "racionalidades absolutas" o el pretendido "fin de la historia".
\end{abstract}

Palabras clave

Juan Carlos Garavaglia - Estado - anti-nacionalismo utopía - otredad - tolerancia cultural

\section{Abstract}

Through the remembrance of personal experiences and the dialogue with the memories of Juan Carlos Garavaglia, Una juventud en los años sesenta, the authors reflect upon the issues that concerned him, as a historian and as a man committed with the social reality of his time. The dialogue revolves around the research subjects of the authors of this article: in the first place, the utopia, rather understood as a politic impulse toward the future than as a specific literary genre; secondly, the Otherness of the gipsy ethnics, as the historically excluded society they signify; and, finally, a complex vision of the State. They underline the cultural pluralism and the intellectual tolerance of Juan Carlos, and suggest breaking the same barriers he fought against: those imposed by "nationalisms", "absolute rationalities" or the presumed "the end of History".

Key words

Juan Carlos Garavaglia - State - anti-nationalism utopia - Otherness - cultural tolerance

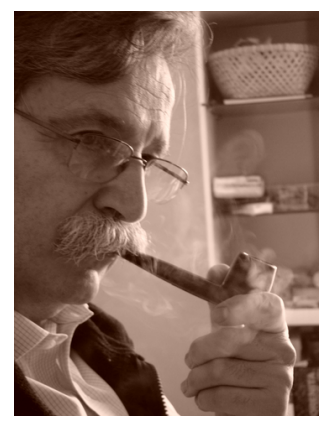

Recibido con pedido de publicación el 21 de septiembre de 2017

Aceptado para su publicación el 15 de noviembre de 2017

Versión definitiva recibida el 22 de diciembre de 2017

Juan Pro, Universidad Autónoma de Madrid, España; e-mail: juan.pro@uam.es María Sierra, Universidad de Sevilla, España; e-mail: $\underline{\text { msierra@us.es }}$ Internacional

Pro, Juan - Sierra, María “Entre el Estado y la utopía, entre la nación y la otredad: un diálogo con el joven Garavaglia de los años sesenta", Prohistoria, Año XX, núm. 28, Homenaje a Juan Carlos Garavaglia, dic. 2017, pp. 165-179. 
Este es un texto que desearíamos no haber escrito. Aun a pesar de que llevábamos mucho tiempo queriendo escribir juntos sin lograrlo. Nuestros respectivos proyectos de investigación se han cruzado en varias intersecciones que nos han llevado a imaginar posibilidades de colaboración apetecibles, pero siempre pospuestas por las urgencias de otros compromisos, de otros trabajos más obligados. Algunas de estas ideas siguen esperando pacientemente su momento; otras perdieron definitivamente su tren, como la generosa invitación de Elisa Caselli para participar en su libro Justicias, agentes y jurisdicciones, invitación a la que no pudimos responder.

Es tan triste y tan creativo como la vida misma que materialicemos el deseo de escribir juntos en esta pequeña contribución a un dosier de homenaje tras la muerte de un amigo como Juan Carlos Garavaglia. Nos ha sido muy difícil encontrar la manera de hacerlo. Las formas en las que hemos conocido a Juan Carlos y nos hemos encontrado con su trabajo han sido muy distintas en nuestro caso: uno de nosotros tuvo la suerte de tratar con él de forma intensa en el contexto del proyecto de investigación europeo $S B L A,{ }^{1}$ que él dirigía, estableciendo esa peculiar relación que combina admiración intelectual y amistad, tan poco frecuente como grata; otra tuvo la contraria escasa fortuna de conocerle solo en los últimos años de su vida y empezar a intuir cómo de cálido era el abrazo que Juan Carlos abría para los amigos y colegas.

El cariño de Eli nos ha empujado a persistir en este propósito de buscar alguna manera para colaborar en un libro de homenaje; $y$, tras intentar (y desechar) varias fórmulas centradas en aquellos aspectos de la obra de Juan Carlos Garavaglia que no resultaban en principio más cercanos por razones de nuestra propia investigación, nos decidimos por dialogar con él a través de Una juventud en los años sesenta, sus memorias de unos tiempos que le conformaron como persona y de los que tuvo necesidad de dar cuenta. ${ }^{2}$ Es el suyo un ejercicio de escritura tan lleno de vida que duele leerlo desde la ausencia de quien lo ejecutó; pero este libro es también una caja de resonancia que nos devuelve su voz inteligente, irónica y comprometida.

Cuando le conocimos personalmente, Juan Carlos Garavaglia estaba involucrado en aquel importante proyecto sobre la construcción de los estados nacionales en América Latina. Procediendo, como procedía, de una larga trayectoria profesional en el paradigma de la historia económica y social de impronta francesa, la cuestión del Estado se le había acabado imponiendo como decisiva para responder a las grandes preguntas que le suscitaba la realidad latinoamericana y argentina. Abordando con el horizonte teórico de la historia total esta cuestión del Estado, que la nouvelle histoire había dejado en un segundo plano, el gran especialista en historia agraria que era Juan Carlos buscaba dar un salto definitivo hacia la clarificación de las formas de ejercicio del poder que han marcado la evolución de América Latina hasta llegar al presente. Con el importante matiz, coherente con su cosmopolitismo vital, de que la revisión de los procesos de construcción estatal la emprendía sin asomo de nacionalismo historiográfico alguno, más bien proponiendo alternativas para superar los relatos ensimismados que, desde el siglo XIX hasta la actualidad, siguen dominando las diferentes historiografías nacionales, puestas al servicio de la legitimación de sus respectivos estados.

\footnotetext{
${ }^{1}$ A Comparative History of the State Building process in Latin America (1820-1870), European Research Council Advanced Grant 230246 (2008 SH-6), Universitat Pompeu Fabra de Barcelona, 2009-2013. http://statebglat.upf.edu/

${ }^{2}$ GARAVAGLIA, Juan Carlos Una juventud en los años sesenta, Prometeo, Buenos Aires, 2015.
} 
Al abordar el estudio de la construcción de los estados nacionales en la América Latina del XIX desde un proyecto del European Research Council y bajo la dirección de un historiador residenciado académicamente entre París y Barcelona, se trataba de ir más allá de mostrar un conjunto de excepcionalidades periféricas. La ambición que Juan Carlos albergaba -aunque se cuidara muy mucho de proclamarlo- era la de desafiar los paradigmas dominantes sobre la construcción de los estados, paradigmas invariablemente basados en la experiencia excepcional de unos cuantos países-centro (Francia, Gran Bretaña, Estados Unidos...) tomados como modelos. Y ahí nos encontramos, compartiendo preocupaciones intelectuales que desbordaban ampliamente lo académico y tenían que ver con el futuro de nuestros respectivos países.

La opción tardía por concentrar la atención sobre la cuestión del Estado, que había sido en gran parte también la nuestra durante años, parecía situar a Garavaglia en el regreso a un terreno historiográfico convencional. Después de todo, el Estado es lo institucional, la manifestación más formal y aparente del poder y de su voluntad de perpetuación. El mismo término de estado, del latín status y del indoeuropeo stā, remite a lo que está en pie: lo dado, lo inmutable (de ahí tantas palabras corrientes en esta lengua nuestra, que tanto amaba Gara: desde el verbo estar hasta estabilidad, estático, estación, establecido, estatuto, institución, persistir, destino y, por supuesto, estado). ${ }^{3}$ Si a esto unimos que el Estado había sido el objeto privilegiado -casi único- de la historiografía tradicional hasta mediados del siglo XX y que, por el carácter nacional de los estados, la visión "nacional" parecía ser la más propia -casi inevitable- para abordar esta cuestión, tenemos todos los elementos para considerar que en esta vuelta al Estado hubiera una renuncia a la tensión crítica y emancipadora que animó desde el comienzo la producción historiográfica de Juan Carlos.

Esa interpretación sería, sin embargo, un espejismo, injusto además de falaz. El Estado venía a ser la última vuelta de tuerca en el intento de comprensión de la realidad histórica latinoamericana, que había procedido de abajo hacia arriba, partiendo del mismísimo suelo de todos los Arecos que como los Macondos- constituyen el continente. ${ }^{4}$ Pero el intento que no podía pararse ahí, y buscaba dar una interpretación al poder cupular de los estados nacionales. ${ }^{5}$ Una interpretación crítica, nada convencional, que develara las

\footnotetext{
3 ROBERTS, Edward A. y PASTOR, Bárbara Diccionario etimológico indoeuropeo de la lengua española, Alianza Editorial, Madrid, 1996, pp. 167-169.

${ }^{4}$ Nos referimos aquí a la larga producción de Garavaglia dedicada a la historia económica y social del mundo agrario argentino y de otros países latinoamericanos, simbolizada en la obra con la que cerró ese ciclo: GARAVAGLIA, Juan Carlos San Antonio de Areco, 1660-1880, Prohistoria, Rosario, 2009. Podríamos, igualmente, citar En busca de un tiempo perdido. La economía de Buenos Aires en el país de la abundancia, 1750-1865 (Prometeo, Buenos Aires, 2004, ed. con Raúl Fradkin), Pastores y labradores de Buenos Aires: una historia agraria de la campana bonaerense 1700-1830 (Ediciones de la Flor, Buenos Aires, 1999), Puebla desde una perspectiva microhistórica: la villa de Tepeaca y su entorno agrario: población, producción e intercambio, 1740-1870 (Claves Latinoamericanas, México, 1994, con Juan Carlos Grosso), Población, sociedad, familia y migraciones en el espacio rioplatense: siglos XVIII y XIX (Cántaro, Buenos Aires, 1993, con José Luis Moreno), Hombres y mujeres de la colonia (Sudamericana, Buenos Aires, 1992, con Raúl Fradkin), Economía, sociedad y regiones (Ediciones de la Flor, Buenos Aires, 1987), Mercado interno y economía colonial (México, Grijalbo, 1983; reeditado en Prohistoria, Rosario, 2009)...

${ }^{5}$ La cuestión del Estado había ido apareciendo bajo diferentes formas en la producción historiográfica de Garavaglia: desde el punto de vista de la fiscalidad, como en Las alcabalas novohispanas, 1776-1821 (Archivo General de la Nación, México, 1988, con Juan Carlos Grosso); desde el punto de vista de la justicia, como en Loi, justice, coutume: Amérique et Europe latines, $16^{\text {e- }}$ $19^{e}$ siècles (EHESS, París, 2005, ed. con Jean-Frédéric Schaub); y, por supuesto, en el libro con el
} 
apariencias discursivas e institucionales acumuladas -como si fueran explicaciones- por las historiografías nacionales y por el discurso oficial de los estados mismos, indiferenciadamente. En esa interpretación, pasaban a primer plano las relaciones de poder no previstas en los textos legales, poniendo de manifiesto geometrías políticas y administrativas bien distintas de las que cuenta la historia patria. Esto servía tanto para Argentina como para México, para Francia como para España, los cuatro países en los que discurrió la trayectoria vital de este historiador.

Juan Carlos Garavaglia era muy historiador. Poco dado a formular teorías, se pronunciaba con la modestia de quien observa hechos singulares y nos los pone ante la vista, para que tengamos la alegría de creer que descubrimos por nosotros mismos lo que significan y en qué medida desafían las explicaciones establecidas. A veces, esto suponía que el valor de sus aportaciones quedaba voluntariamente velado por una mezcla de prudencia y discreción, como esperando a que alguien más osado viniera a señalar la importancia de lo dicho.

Algo así pudo pasar también con esta gran investigación colectiva sobre el Estado a la que nos estamos refiriendo. La investigación consistió en impulsar un conjunto brillante de tesis doctorales sobre la construcción del Estado en varios países de América Latina; ${ }^{6}$ y, alrededor de ese eje, ir proponiendo discusiones trasnacionales sobre cuestiones clave como la fiscalidad, los catastros, la burocracia, la guerra o la justicia, en las que afloraba el sentido de conjunto del proyecto. ${ }^{7}$ Incluso en esa parte de la investigación, el protagonismo nos lo concedía a otros, invitándonos generosamente a compartir la reflexión y la discusión, la ocasión de generalizar y de alcanzar conclusiones casi teóricas. La generosidad de Juan Carlos se mostraba en todos los pasos del proyecto, sugiriendo, impulsando, invitando, abriendo espacios; pero no cabe duda ninguna de que él estaba detrás de cada una de las tesis doctorales que dirigía y detrás de cada uno de los estimulantes diálogos que promovió. ${ }^{8}$

que dio el giro definitivo hacia este tema, Construir el Estado, inventar la nación: el Río de la Plata, siglos XVIII-XIX (Prometeo, Buenos Aires, 2007).

${ }^{6}$ Las tesis fueron seis, todas ellas dirigidas por Juan Carlos Garavaglia y presentadas en 2013: una en la École des Hautes Études en Sciences Sociales de París (Elvira López Taverne: Le processus de construction de l'État au Chili : une étude à travers l'organisation des finances publiques et de la bureaucratie, 1817-1860) y cinco en la Universitat Pompeu Fabra de Barcelona: las de Juan Carlos Sarazúa (Recolectar, administrar y defender: la construcción del estado y las resistencias regionales en Guatemala, 1800-1871), Pablo A. Rodríguez Solano (Cambio y continuidad: la hacienda pública como factor de construcción estatal, Costa Rica 1812-1859), Mario Etchechury (Hijos de Mercurio, esclavos de Marte: mercaderes y servidores del estado en una frontera sud-atlántica: Montevideo, 1806-1860), Viviana Velasco Herrera (Negociar el poder: Fiscalidad y administración pública en el proceso de construcción del Estado ecuatoriano, 1830-1875) y Evangelina de los Ríos (Hacia un nuevo orden fiscal: las formas de recaudación impositiva: instituciones, agentes y recursos: Santa Fe, Argentina, 1852-1873).

7 Las reuniones del proyecto de las que tenemos noticia fueron siete: tres en Barcelona (2009, 2010 y 2011) y cuatro en América: Montevideo-Buenos Aires (2010), San José de Costa Rica (2011), Santiago de Chile (2011) y Quito (2012).

8 Estos trabajos quedaron recogidos en un libro del propio Garavaglia (La disputa por la construcción nacional argentina. Buenos Aires, la Confederación y las provincias, 1850-1865, Prometeo, Buenos Aires, 2015) y en siete volúmenes colectivos: GARAVAGLIA, Juan Carlos (ed.) "Recaudar y reconstruir el Estado", dosier en Illes $i$ imperis, núm. 13, 2010, pp. 7-213; GARAVAGLIA, Juan Carlos y GAUTRAEU, Pierre (eds.) Mensurar la tierra, controlar el territorio: América Latina, siglos XVIII-XIX, Prohistoria, Rosario, 2011; GARAVAGLIA, Juan Carlos - PRO RUIZ, Juan - ZIMMERMANN, Eduardo Las fuerzas de guerra en la construcción del Estado: América Latina, siglo XIX, Prohistoria, SBLA-UPF, Rosario, 2012; GARAVAGLIA, Juan Carlos y PRO, Juan (eds.) Latin American Bureaucracy and the State Building Process, 1780-1860, Cambridge 
Esta forma de rehuir la formulación de teorías y de compartir con otros el logro de las conclusiones generales ha podido dejar en penumbra la importancia de la obra de Garavaglia sobre el Estado y, sobre todo, el fuerte compromiso ético que la inspiraba. Desgranado una y otra vez en conversaciones informales, más que en los tiempos de exposición académicos, este corazón de la investigación de Gara solo se comprende a la luz del que fue su último libro, Una juventud en los años sesenta. Un libro muy querido por su autor y que habría merecido más atención de la que se le prestó desde los medios académicos en los que él se había movido siempre.

Tal vez hubo personas en las universidades de Europa y América que pensaran que este era un libro "privado" de Garavaglia, una especie de "ajuste de cuentas" con su pasado personal, escrito para sus hijos más que para ser discutido en la comunidad científica; y que lo contrapusieran a los trabajos "públicos", llenos de seriedad académica, a los que el autor nos tenía acostumbrados. Como si lo público y lo privado se pudieran separar así, sin más, con un corte limpio de la navaja de Ockham. Como si la historia y la memoria no hubieran llegado a entrelazarse en nuestros días hasta hacer del trabajo del historiador algo infinitamente más vivo, más rico y más complejo de lo que fue en otros tiempos. Como si el propio Garavaglia no hubiera hablado de la urgencia que tenía por escribir este libro en una de las reuniones de balance del proyecto State Building in Latin America, en Quito (Ecuador), en octubre de 2012. Hasta tal punto consideraba ligados los dos empeños que, por entonces, estaba intentando culminar a la vez el libro recapitulativo de su vida y el proyecto de investigación sobre el Estado, el libro de las experiencias que generan preguntas y el trabajo de investigación en busca de respuestas.

En Una juventud de los años sesenta se encuentran las experiencias vitales que llevaron a Juan Carlos Garavaglia a hacerse historiador, un cierto tipo de historiador crítico e inquieto, como parte de un impulso más amplio para comprender el mundo y transformarlo en un lugar mejor. Abundando en el convencimiento de que este último libro de Gara es especialmente valioso, al reunir las razones de historiador con la necesidad personal de rendir(se) determinadas explicaciones, leer o releer ahora estas memorias de juventud se ha convertido para nosotros, antes que nada, en un acto de homenaje privado. Ha sido también un acto de duelo íntimo, porque, de forma explícita o entre líneas, hay en este libro muchas ocasiones para sentir la ausencia de un amigo: duele la dedicatoria personal, fechada en Argelès-sur-Mer; duele la dedicatoria en letra impresa a la compañera Elisa, que supo de lo difícil del proceso de

Scholars, Newcastle, 2013; CONTENTE, Claudia (ed.) “Justicia, violencia y construcción estatal”, dosier en Illes i imperis, núm. 15, 2013, pp. 7-193; GARAVAGLIA, Juan Carlos BRADDICK, Michael J. and LAMOUROUX, Christian (eds.) Serve the Power(s), Serve the State. America and Eurasia, Cambridge Scholars Publishing, Cambridge, 2016; y CASELLI, Elisa (coord.) Justicias, agentes y jurisdicciones. De la Monarquía Hispánica a los Estados Nacionales (España y América, siglos XVI-XIX), Fondo de Cultura Económica, Madrid, 2016. Y también en las cinco monografías publicadas a partir de las investigaciones doctorales y posdoctorales de los miembros del equipo: LÓPEZ TAVERNE, Elvira El proceso de construcción estatal en Chile: hacienda pública y burocracia, 1817-1860, Dibam-Centro de Investigaciones Diego Barros Arana, Santiago de Chile, 2014; LÓPEZ BEJARANO, Pilar Un Estado a crédito: Deudas y configuración estatal de la Nueva Granada en la primera mitad del siglo XIX, Universidad Javeriana, Bogotá, 2015; ETCHECHURY BARRERA, Mario Hijos de Mercurio, esclavos de Marte. Mercaderes y servidores del Estado en una frontera sud-atlántica: Montevideo, 1806-1860, Prohistoria, Rosario, 2015; RODRÍGUEZ SOLANO, Pablo A. La cuestión fiscal y la construcción del Estado de Costa Rica, 18211859, Universidad de Costa Rica, San José, 2017; DE LOS RÍOS, Evangelina Gobernar es cobrar. Política fiscal, recaudación impositiva y cultura tributaria. Santa Fe, Argentina, 1855-1873, Prohistoria, Rosario, 2017. 
escritura; duele esa afirmación por parte del escritor de ser alguien con "más pasado que futuro" ... ${ }^{9}$ Cierto que es un dolor bueno para poder despedirnos de Gara.

Pero la lectura nos regala otras muchas cosas. Para empezar, nos devuelve por momentos a su autor -a veces, leyendo ideas tan sinceras o tan atractivas, uno se encuentra sin darse cuenta diciéndose "tengo que comentarle que..."-; un autor especialmente presente en un libro del que es, además de la voz de un narrador que casi puede oírse físicamente, el sujeto protagonista. Pero, más allá de eso, se ha convertido para nosotros en la ocasión inesperada de encontrar en un libro cerrado un paradójico interlocutor para nuestros planes de futuro. Porque Juan Carlos nos obsequia ocupándose -y mucho- de los dos temas en torno a los cuales recientemente venimos organizando nuestros respectivos proyectos de investigación, por más que parezcan a priori alejados de su biografía intelectual: la utopía, entendida como impulso político hacia el futuro antes que como un específico género literario; y la otredad de un pueblo históricamente castigado por la exclusión, como es el gitano, de alguna extraña manera cercano al espíritu cosmopolita y errante de Juan Carlos.

Las experiencias de las que Juan Carlos nos habla en este libro tienen que ver sobre todo, obvio es decirlo, con la rebeldía ante la injusticia social, la desigualdad, la represión, la violencia y los abusos de poder que marcaron a toda su generación, en Argentina quizá con especial virulencia. Frente a aquella experiencia fuerte del Estado, sentido como víctima y como militante, aparece el Juan Carlos utópico, que sueña -al igual que muchos de sus compañeros de aquellos años- con una Argentina mejor como parte de un mundo mejor. La utopía de futuro, que puede tener mil nombres según el momento y el lugar, según el partido que a cada uno le haya sido posible tomar, está expuesta negro sobre blanco en ese libro valiente que es Una juventud de los años sesenta.

Algunas versiones concretas de esas utopías en las que creyó Juan Carlos en su juventud fueron las que le llevaron a militar en organizaciones revolucionarias cuyo sentido resulta tan difícil explicar hoy, pasado el tiempo, a las generaciones actuales (ese era, precisamente, uno de los objetos de escribir este libro). Otras versiones de la utopía de un mundo mejor le llevaron a convertirse en historiador -cuando todo le encarrilaba hacia el ejercicio profesional del Derecho, dedicación sensata- y a hacer de la investigación del pasado su arma de futuro, un arma mucho más propia de su humanidad que la que se vio empuñando un día en una calle de Bahía Blanca, encañonando a una vecina que salía de su casa con la bolsa de la feria. ${ }^{10} \mathrm{Y}$ nunca dejó de ejercitar esa veta utópica que tenía muy arraigada: cuando, como profesor de la Universitat Pompeu Fabra de Barcelona, entre 2008 y 2014, tuvo que enfrentarse reiteradamente a la ascensión del nacionalismo catalán en la Universidad y en la calle, una espiral en la que, llegado un momento, asomaba el núcleo duro del fascismo; e igualmente cuando, conmovido por los atentados yihadistas de París de 2015, decía sentir que lo que había sido atacado y estaba bajo amenaza era la República, así, con mayúsculas, es decir, esos valores republicanos que, a pesar de todos los pesares, encarnaba Francia para él.

Por encima del descreimiento que dan los años y las decepciones de la vida, seguir creyendo en que tiene sentido soñar con utopías es algo que está al

\footnotetext{
${ }^{9}$ GARAVAGLIA, Juan Carlos Una juventud..., cit., p. 11.

${ }^{10}$ GARAVAGLIA, Juan Carlos Una juventud..., cit., p. 134.
} 
alcance de unos cuantos privilegiados como Juan Carlos. No nos extraña, por tanto, escucharle decir, sabiéndose a contracorriente del tiempo de los millennials:

"Como es sabido, hoy el "sentido común" nos dice que estamos en la época del fin de las utopías, pero sospecho que ellas son, en cierto sentido, consustanciales a la condición humana."11

La expresión "fin de las utopías" es una referencia a un autor tan influyente para la juventud de los sesenta como Marcuse. ${ }^{12}$ Pero fue después de la caída del Muro de Berlín (1989) y de la desaparición de la Unión Soviética (1991) cuando se convirtió en un lugar común para describir el tono vital del cambio de siglo, en paralelo con el "fin de la Historia". ${ }^{13}$ Para un historiador consciente, ambas expresiones encierran por igual un desvarío: un error, no por extendido menos error, que remitiría a un sinsentido, si no fuera porque es fácil adivinar detrás la intención de un engaño de grandes proporciones. Garavaglia arremete contra los dos supuestos -el del fin de la historia y el del fin de las utopías- en un mismo pasaje:

"Ninguna sociedad humana "realmente existente" se parece a la saga literaria de Juego de tronos, donde nos encontramos con grupos humanos muy complejos, pero que parecen haberse mantenido estáticos durante milenios, sin cambios tecnológicos, sin visiones de un futuro distinto, sin utopías, en el marco de un medio ambiente y un clima devastador de eterno retorno borgiano. Son sociedades que tuvieron historia, pero no poseen historicidad. En verdad, esto es irreal (...), pues aunque pueda suceder a velocidad muy diversa, una de las características de las sociedades humanas es el cambio (...). Otra cuestión, relacionada con la anterior, es la proyección hacia el futuro y con frecuencia, esto incluye también al pensamiento utópico. Ese horizonte utópico posee, en cada sociedad y en cada momento, características que le son peculiares. ¿O acaso, las reglas de la competencia perfecta, rigiendo el mercado de forma equilibrada, no son una utopía?"14

La cuestión, pues, está clara: no solo no ha llegado el fin de la Historia con el triunfo del capitalismo sobre el comunismo y la definitiva instauración de un orden imperial americano que impone su modelo sin contestación por todas partes; no solo no ha llegado el fin de las utopías con el desvanecimiento de los viejos ideales de cambio y la constatación, supuestamente sagaz, de que cualquier intervención radical para mejorar la vida de la humanidad conducirá a resultados distópicos como el totalitarismo del desaparecido régimen soviético. Sino que la lección que se puede aprender de una lectura histórica de la segunda mitad del siglo XX es exactamente la contraria: por un lado, que la historicidad es consustancial a las sociedades humanas, puesto que siempre aparecen en ellas factores de cambio, conflictos, innovaciones e insatisfacciones con lo existente; por otro lado, que esa historicidad viene implícita en otro rasgo no menos universal de las sociedades humanas, que es el impulso utópico, la tendencia a imaginar formas ideales de convivencia que superen los problemas

\footnotetext{
${ }^{11}$ GARAVAGLIA, Juan Carlos Una juventud..., cit., p. 35.

${ }^{12}$ MARCUSE, Herbert La fin de l'utopie, Seuil, París, 1968.

${ }^{13}$ FUKUYAMA, Francis “The End of History?”, The National Interest, núm. 16, 1989.

${ }^{14}$ GARAVAGLIA, Juan Carlos Una juventud..., cit., pp. 35-36.
} 
del presente. Esa fe en un futuro mejor, que es lo que sucintamente hemos dado en llamar utopía, canaliza los impulsos de cambio que existen en toda sociedad, dándole forma de programas políticos, obras literarias sobre islas imaginarias o experiencias comunitarias modélicas; y va de la mano con el dinamismo de la historia, por más que adopte formas distintas en cada contexto cultural (en puridad, la Utopía sería solo la forma concreta que este impulso idealista ha adoptado en la modernidad occidental, desde la época del Renacimiento, cuando Tomás Moro le dio nombre en 1516).

El comentario de Juan Carlos, sin embargo, iba más allá de esta constatación de que la Historia continúa (y la utopía también). Incorpora en su última frase la devolución de la acusación contra el acusador, en un inesperado ardid del abogado que pudo haber sido. Frente al establishment capitalista de siempre, que acusa de ser meras utopías $-y$, por lo tanto, peligrosas fantasías irresponsables- a las ideas de futuro en las que Garavaglia y otros habían creído desde los años sesenta, el acusado se revuelve y dice: ¿acaso no proceden de utopías igualmente irrealizables los modelos que han inspirado y legitimado vuestro propio sistema? ¿Acaso el capitalismo ahora triunfante no fue, en su momento, la utopía de unos cuantos pensadores que proponían mercados autorregulados que producirían la riqueza de las naciones, manos invisibles que nos harían felices a todos? ¿Acaso, como podría decirse de otras utopías, no ha sido esta del capitalismo igualmente utilizada para legitimar un orden de cosas injusto, una distopía en la que nos hallamos sumergidos desde hace años? No, no es el capitalismo triunfante del siglo XXI el plan sensato de los hombres razonables frente a las locas ensoñaciones de quienes creen en utopías. Aquí, Garavaglia reivindica el sentido que tuvieron las revoluciones en las que creyó y las utopías en las que siguió creyendo; y pone en su sitio al neoliberalismo dominante, recordándole que no es otra cosa que la propaganda interesada de los mercaderes que venimos escuchando -mejor o peor vendida-desde tiempos de Adam Smith.

El militante revolucionario que fue Garavaglia practicó la utopía a su manera, que era en gran parte la de su generación. También en el sentido de los experimentos utópicos limitados como prefiguración de la sociedad ideal que se pretende para todos en el futuro (el mismo que dio nombre a los "socialistas utópicos" en las palabras de Engels). ${ }^{15}$ Cuando, en 1968, fue detenido y pasó varias semanas en la cárcel de Ezeiza, nos cuenta cómo la vida del pequeño grupo de presos políticos se acomodaba a los ideales compartidos sin esperar al hipotético triunfo de la Revolución:

“Todos discutíamos con todos. Yo hice unas cuantas charlas de historia argentina para un pequeño grupo. Nos habíamos organizado para hacer por turnos todas las tareas para mantener el lugar lo mejor posible; para nosotros, esa forma de hacer las cosas en común, prefiguraba en cierto modo la sociedad que queríamos construir, igualitaria, con fuerte consciencia política y altamente solidaria."16

Claro que no dejaba de ver con realismo que, incluso en los falansterios mejor avenidos, la insolidaridad y el egoísmo de los seres humanos aparece

\footnotetext{
${ }^{15}$ ENGELS, Federico Del socialismo utópico al socialismo científico, Ricardo Aguilera, Madrid, 1969 [1880].

${ }^{16}$ GARAVAGLIA, Juan Carlos Una juventud..., cit., p. 143.
} 
para poner en cuestión los límites del experimento utópico. Un utópico consciente lo sabe y esta constatación forma parte de su sentido crítico de la realidad, que también se aplica a los propios sueños:

"Pero, siempre había excepciones, aquellos que hacían lo posible para no poner el hombro cuando les tocaba, lo que mostraba los límites concretos de la solidaridad, incluso entre camaradas políticamente comprometidos."17

El sentido de lo utópico aparece explicitado en el capítulo Dos de Una juventud en los años sesenta, cuando Juan Carlos describe su doble vida en Bahía Blanca como profesor de Historia en la Universidad y como militante de Montoneros. Una doble vida que él entendía estrechamente conectada, pues se trataba de dos dimensiones de la misma lucha por transformar la realidad:

“No, no era sencillo, pero estaba dispuesto a continuar en ambos senderos, convencido de que las dos funciones eran indispensables para el triunfo de ese "mundo mejor" al que aspirábamos. Pensar y actuar eran, según lo entendíamos todos (o casi todos, pues los "fierreros" puros eran también una realidad), dos facetas absolutamente indispensables para seguir en ese difícil baile." 18

Desde luego, Juan Carlos abandonó pronto una de esas formas de actuar y de estar en el mundo, probablemente por su absoluta aversión a los "fierros" y a todo lo que pudiera sonar a armas o violencia. Pero no dejó de creer y de trabajar por su utopía, volcando toda la atención sobre la otra vía, la del trabajo intelectual, en la que continuó hasta el final. Ese programa puede leerse, entre líneas, en todas sus obras. En definitiva, el gran proyecto colectivo que impulsó sobre la historia del Estado tenía tanto de fe en las posibilidades transformadoras de una República verdaderamente igualitaria y democrática como en la denuncia de las fachadas institucionales que, a lo largo de los dos últimos siglos, han servido para encubrir la traslación a la esfera pública de los intereses privados, las desigualdades, la dominación y la explotación características de la sociedad civil. Para ello, sin embargo, tuvo que realizar un largo recorrido, deshaciéndose por el camino de lastres adquiridos con entusiasmo durante la etapa formativa de la juventud, como aquel concepto de "aparato" que tanto juego había dado para el análisis del papel del Estado entre los militantes de su entorno en los años sesenta y setenta. ${ }^{19}$

Por otro lado, las experiencias que laten en Una juventud en los años sesenta tienen que ver también con la profunda trasnacionalidad de su autor, que le hacía ser tan argentino al tiempo que tan francés, totalmente europeo a la par que totalmente latinoamericano, un poco extranjero en todas partes y en todas partes comprometido con lo que merece la pena comprometerse de cada sitio. En este sentido también, se manifiestan en estas memorias de juventud rasgos intelectuales de Juan Carlos Garavaglia que nos parece especialmente valioso rescatar. No son temas intencionados que se presenten de forma directa; quedan más bien cobijados entrelíneas, en comentarios espigados aquí y allá.

${ }^{17}$ GARAVAGLIA, Juan Carlos Una juventud..., cit., p. 143.

${ }^{18}$ GARAVAGLIA, Juan Carlos Una juventud..., cit., p. 46.

${ }^{19}$ El libro de Louis Althusser: Ideología y aparatos ideológicos del Estado (Nueva Visión, Buenos Aires, 1974) constituyó un referente para toda una generación. Garavaglia se refiere a él con cierta sorna en Una juventud de los años sesenta (p. 67) como ejemplo de esa concepción "aparatista". 
Pero son vetas que florecen con frecuencia y se entrecruzan hasta tejer un marco común de inteligibilidad. Porque se trata de constantes vitales de largo recorrido que, nacidas en el tiempo de la infancia y la juventud, se mantuvieron en la madurez de Juan Carlos, como retrata el libro del que hablamos -escrito, no lo olvidemos, desde su presente de 2015-. Nos referimos al gusto por la pluralidad cultural, el nomadismo vital e intelectual, la tolerancia hacia lo distinto y, en definitiva, lo que podríamos llamar su conciencia de la otredad.

Todos los que le conocimos sabíamos que Gara, nacido en Pasto (Colombia) y porteño de crianza, gustaba presumir de este mestizaje de origen. El libro recuerda pequeñas ocasiones aprovechadas para llevar la contraria a nacionalistas banales, como ese baile en el barrio de Lanús en el que pretendieron provocarle desde alguna clase de masculinidad patriótica. Amante intenso de la Argentina, pero preocupado por "preservarme del nacionalismo obtuso", encontró su talismán en lo que llama su "pasado simbólico latinoamericano". ${ }^{20}$ Este pasado no es sino la trasnacionalidad de sus primerísimos años: el itinerario de Colombia a Guatemala para luego retornar en un viaje que no puede literalmente recordar, pero que forma parte de la construcción de su memoria- al Buenos Aires del que habían partido sus padres. Al leerle ahora, nos resurgen entre los recuerdos de nuestra propia infancia esos mitos clásicos que nos contaban historias de héroes que de recién nacidos quedaron bendecidos con poderes especiales: como Aquiles o Hércules, Gara quedó protegido, en su caso del virus del chauvinismo, por una madre titiritera capaz de transmutarse en abogada obrerista. Pura magia.

En sus tiempos de escolar, el niño Juan Carlos pareció buscar amistades que profundizaran su trasnacionalidad de nacimiento. Argentina, ese país que había sido receptáculo generoso de una diversísima inmigración, le obsequió con ocasiones para ello: sus amigos irlandeses del St. Lucy English School fueron, según nos cuenta, una familia de elección; ${ }^{21}$ pero también sus pandillas de verano en Villa Gesell estaban formadas por amigos "casi todos hijos de extranjeros (franceses, italianos, ingleses, alemanes, austriacos, suizos, etc.)" ${ }^{22} \mathrm{Si}$ dibujásemos un mapamundi de los orígenes culturales y nacionales de las amistades de juventud de Garavaglia, sería muy fácil entender una de las andanadas finales del libro: la crítica a "la manía descalificatoria" que disfraza la discrepancia ideológica con el argumento hipócrita de que las ideas de los otros son "exóticas" en tanto que ajenas a la tradición interna de una determinada sociedad, a la que supuestamente pondrían en peligro de disolución. ${ }^{23}$

Pero, además, está ese nomadismo vital e intelectual que practicó toda su vida. Obligado, en ocasiones, voluntario en otras, sacando partido para aprender y crecer en todas. Ese mundo simbólico latinoamericano de su juventud se vio ampliado en sentido transoceánico, cuando implicó a Europa hasta hacer de su universo familiar un espacio de dos orillas. Sin duda, la experiencia francesa formó parte sustancial de la lectura positiva del transterramiento que Gara fue capaz de hacer. Y su amor por la cultura francesa también late en este libro, desde las expresiones más eminentemente historiográficas (ese libro de Marc Bloch" que le hace "tocar el cielo con las

\footnotetext{
${ }^{20}$ GARAVAGLIA, Juan Carlos Una juventud..., cit., p. 22.

${ }^{21}$ GARAVAGLIA, Juan Carlos Una juventud..., cit., pp. 56-57.

${ }^{22}$ GARAVAGLIA, Juan Carlos Una juventud..., cit., p. 111.

${ }^{23}$ GARAVAGLIA, Juan Carlos Una juventud..., cit., p. 206.
} 
manos" ${ }^{\prime 25}$ ) hasta otras manifestaciones que hablan de una cultura habitada en primera persona. En el último sentido pueden entenderse las palabras o expresiones en lengua francesa que Gara emplea a lo largo de su relato, cuando en ocasiones le resulta más sencillo y preciso usar fórmulas como ca va de soi, beau parler o le coeur $n^{\prime} y$ était pas. ${ }^{26}$ Precisamente su aprecio -en general- por las lenguas diversas en las que se manifiesta la cultura de la vieja Europa constituye otro dato fundamental de su nomadismo intelectual:

"Haber extendido mis lenguas me permitió gozar mejor de la buena literatura y recuerdo muy bien cuando pude empezar a leer literatura en italiano, portugués o catalán (¡ah, Josep Pla!); cada lengua nueva nos abre un mundo desconocido y lleno de novedosos tesoros." 27

Encontrar tesoros pasando de un idioma a otro es propio solo de quienes no temen salir de las propias fronteras intelectuales; de igual manera que, a la inversa, lo es también el elogio del latín como lengua madre de las romances y maestra para una escritura cuidada -elogio elevado al recordar a aquel profesor Pagés dispuesto a acoger en su clase a "revoltosos y subversivos" perseguidos por la Guardia de Infantería. ${ }^{28}$

La capacidad de atravesar linderos y la resistencia a quedarse atrapado en la comodidad de lo conocido es aún más expresa en su voluntad de superar fronteras disciplinares; tal como declara en un momento del libro, siempre desconfió de ellas y por ello la École des Hautes Études en Sciences Sociales de París, donde trabajo de forma estable entre 1991 y 2009, siempre le pareció "un paraíso en este sentido". ${ }^{29}$ Juan Carlos Garavaglia asumió el movimiento y el cambio como datos naturales de la vida intelectual: quizá las horas pasadas de niño tumbado boca arriba sobre la hierba en el campito de San Vicente, viendo pasar bandadas de pájaros y sintiendo la libertad, le educaron para ello.

No hay contradicción alguna entre ese cosmopolitismo intenso, aprendido desde la infancia, y el no menos intenso amor por la patria, entendida como el país en el que se vive y cuyos valores se comparten. El amor por la Argentina, que fue el que le llevó a integrarse en Montoneros en 1973; ${ }^{30}$ pero también el amor por Francia, patria de acogida que identificaba en los principios republicanos de libertad, igualdad y fraternidad, tanto como en su estimulante vida intelectual y en la calidez del refugio que se construyó en Argelès-sur-Mer. Argentina, país de inmigrantes, es como un resumen del mundo; Francia, el país que hizo de sus derechos del ciudadano los derechos del hombre en sentido universal, es idealmente la utopía de la comunidad de ciudadanos igualados por la Ley con independencia de su origen o de su condición.

Si uno repasa las personas que concurrían a las reuniones académicas que convocaba Juan Carlos, durante los años que duró el proyecto del ERC

\footnotetext{
${ }^{24}$ Referencia a: BLOCH, Marc La sociedad feudal, Uteha, México, 1958 (2 vols.). Treinta años más tarde, lo releyó Gara en su lengua original: La société féodale, Albin Michel, París, 1939-1940, (2 vols.).

${ }^{25}$ GARAVAGLIA, Juan Carlos Una juventud..., cit., pp. 60-61.

${ }^{26}$ GARAVAGLIA, Juan Carlos Una juventud..., cit., pp. 73, 75 y 101 respectivamente.

${ }^{27}$ GARAVAGLIA, Juan Carlos Una juventud..., cit., p. 98.

${ }^{28}$ GARAVAGLIA, Juan Carlos Una juventud..., cit., pp. 130-131.

${ }^{29}$ GARAVAGLIA, Juan Carlos Una juventud..., cit., p. 129.

${ }^{30}$ GARAVAGLIA, Juan Carlos Una juventud..., cit., p. 23.
} 
sobre la construcción del Estado en América Latina (2009-2014), se da cuenta de que en ellas había construido esa utopía del diálogo entre gentes muy distintas, venidas de diferentes países y continentes, y frecuentemente de áreas científicas y tradiciones de investigación también diferentes. Si el pequeño núcleo central de jóvenes que reunió Gara a su alrededor era ya una especie de falansterio o de New Harmony académico, formado por un uruguayo, una colombiana, una chilena, una argentina, un costarricense, un guatemalteco y una ecuatoriana; ${ }^{31}$ el horizonte se ampliaba con los miembros "asociados" del proyecto, entre los que había dos personas de la EHESS de París, dos de universidades españolas, dos de Argentina y una más de Brasil. ${ }^{32}$ Pero la verdadera Babel creativa se organizaba con motivo de las reuniones temáticas, en donde, además de los "fijos" ya mencionados, aparecían investigadores de Gran Bretaña, Italia, Portugal, México, y una nutrida representación de Argentina, de Francia y de España. ${ }^{33}$

Junto con el nomadismo intelectual y el gusto por la pluralidad cultural, las memorias de juventud de Gara hablan -fuerte- de la aceptación del "otro", manifestando una tolerancia hacia la diferencia que él apreció especialmente en algunas personas que se encontró en su camino y eran portadoras en grado sumo de esta cualidad. Desde luego que esta actitud tenía que ver con su compromiso social; pero también con una temprana conciencia de que la definición de la identidad propia no deja de pasar por la construcción de una otredad para los que nos resultan diferentes. Así, el viaje de los "camiones artísticos" que le sacó de su mundo escolar relativamente privilegiado en edad muy temprana, fue, tal y como lo recuerda, una experiencia que le mostró la diversidad del país que había más allá de la burbuja urbana de Buenos Aires:

"Este viaje, a mis quince años adolescentes, fue un muestrario de ese pedazo de la Argentina que me dejó con innumerables preguntas y unas pocas respuestas, pero que me dio una buena aproximación a ese país 'real'". ${ }^{34}$

\footnotetext{
${ }^{31}$ Respectivamente: Mario Etchechury, Pilar López Bejarano, Elvira López Taverne, Evangelina de los Ríos, Pablo Rodríguez Solano, Juan Carlos Sarazúa y Viviana Velasco (a quienes citamos en estricto orden alfabético). Claudia Contente, argentina, supervisaba el equipo en calidad de coordinadora científica.

32 Respectivamente, Pierre Gautreau y Alejandro Rabinóvich (EHESS), Juan Pro (Universidad Autónoma de Madrid) y Enric Ucelay-Da Cal (Universitat Pompeu Fabra de Barcelona), Rodolfo González Lebrero (Universidad de Buenos Aires / Universidad Nacional de Luján) y María Fernanda Barcos (Universidad Nacional de La Plata), y Mariana Flores da Cunha Thompson Flores (Pontificia Universidade Catolica de Riogrande do Sul).

${ }^{33}$ Entre los habituales de Argentina se encontraba Jorge Gelman, de quien acabamos de conocer la triste noticia de su muerte, en el mismo año que su amigo Juan Carlos Garavaglia. También Elisa Caselli, Raúl Fradkin, Eduardo Zimmermann, Horacio Crespo, Silvia Ratto, Darío Barriera, Marta Bonaudo, Diego Roldán, Mariana Canedo, Guillermo Banzato, María Cecila Rossi. Entre los franceses, Christian Lamouroux, Guillaume Carré, Romain Huret, Jérémie Barthas, Claudio Ingerflom (en realidad de origen argentino) y Kapil Raj (venido de la India). Entre los de España, Josep Maria Delgado, Albert García Balañá, Martín Rodrigo Alarilla, Eloy Martín Corrales, Josep Maria Salrach, Jaume Torras, Josep Maria Fradera y José Javier Ruiz Ibáñez. Entre los británicos, Michael Braddick, Natalia Sobrevilla (del Perú) y Stephen Jacobson (este último en la UPF). De Italia, Gaetano Sabatini. De Portugal, Pedro Cardim. De México, Luis Jáuregui y Arturo Taracena (este último de origen guatemalteco). También concurrieron investigadores de Brasil (Wilma Peres Costa, Andrea Slemian y Helén Osorio), Ecuador (Eduardo Kingman y Valeria Coronel), Costa Rica (Víctor Hugo Acuña y Esteban Corella), Uruguay (Ana Frega) y Chile (Luis Ortega).

${ }^{34}$ GARAVAGLIA, Juan Carlos Una juventud..., cit., p. 80.
} 
La aceptación del otro se acomoda en el útero de la tolerancia a lo largo de la juventud recordada en estas memorias. En más de un recuerdo, Gara eleva a la más alta calidad humana a aquellas personas que conoció y manifestaron esta cualidad: como al rememorar a Ronnie, el mayor de los hermanos de la familia irlandesa con la que convivió en tiempos escolares, de quien recuerda que era capaz de tratar con la misma tolerancia a su cuñado militar carapintada y a su otro cuñado montonero. ${ }^{35}$ Los espíritus abiertos en los que repara la memoria de Gara son, con frecuencia, personas de una genealogía nacional y cultural mestiza, vacunadas -como él mismo quería estarlo-contra el mal de la verdad absoluta. Por ello, no juzgar a quienes se comportaron de tal o cual manera ante la militancia política y sus tensiones, solo tiene los límites de la decencia moral, que, estos sí, siente muy claramente mientras escribe. En este contexto, "no juzgar" es uno de sus lemas. No sentenciar pero, a la par, ejercer la capacidad crítica (y autocrítica), esa que le llevó separarse de la Orga e intentar salir del vórtice de destrucción en el que perecieron tantos compañeros y compañeras de lucha.

El reconocimiento de la otredad siempre se ayuda del sentido del humor, y de ese iba sobrado Gara. Uno de los principales sustentos del mejor humor que no es el que ridiculiza al "inferior"- es la capacidad de salirse de uno mismo y colocarse en ese lugar insólito que provoca la risa. Una juventud en los años sesenta es un libro tocado por el don de la joda, emplazando al lector una y otra vez al lugar cómplice del humor inteligente: cuando recuerda un control policial en el que se ve atrapado con un compañero -montonero- que "parecía un tipo disfrazado de montonero", ${ }^{36}$ igual que cuando rememora la propuesta de acabar con unos vinitos tras una clase impartida a trabajadores que resultaron ser de un grupo de alcohólicos anónimos, ${ }^{37}$ Gara se está saliendo de sus papeles de militante aguerrido y profesor abnegado para llevarnos con la sonrisa, o con la risa franca, ante la realidad desnuda de la condición humana.

El humor ayudó al propio Juan Carlos a encarar situaciones como ese antisemitismo cotidiano que tan bien retrata su libro cuando aparece el tema. Como en esa charla de café en la que resulta tan fácil identificar su voz y su rostro serio-bromista:

"Lo simpático de llevar un apellido no judío, es que uno puede gozar escuchando el antisemitismo "vulgar", si se puede decir así. Una vez, en el Archivo, un tonto con el que salí a tomar un café, hablando de alguien que yo no conocía, dijo: “¡Y se casó con una judía, te das cuenta!", no puede aguantar y le espeté "Bueno, tengo una madre y una esposa judías así que imagínate cómo lo sé", je, je, se le cayó la mandíbula como en los viejos dibujos animados." 38

Sin llevar un apellido inequívocamente judío ni tampoco sentir como propia esta parte de la herencia cultural-religiosa de una rama de su familia, lo cierto es que la cuestión judía le ayudó a reflexionar sobre la identidad así como sobre los consuelos y las trampas que incluyen las identidades colectivas. Pues, aunque como él mismo dice, la historia familiar hacía que su "judeidad fuera bien escasa", visto desde fuera -y aún más desde un afuera antisemita- "uno es

\footnotetext{
${ }^{35}$ GARAVAGLIA, Juan Carlos Una juventud..., cit., pp. 56-57.

${ }^{36}$ GARAVAGLIA, Juan Carlos Una juventud..., cit., p. 46.

${ }^{37}$ GARAVAGLIA, Juan Carlos Una juventud..., cit., p. 172.

${ }^{38}$ GARAVAGLIA, Juan Carlos Una juventud..., cit., p. 106.
} 
judío y punto". Esta agresión, no necesariamente física pero sí real, le ayuda a introducir en sus memorias de juventud algunas reflexiones sobre la condición de las minorías y sobre los procesos de racialización, acercando el caso de los judíos al de otros colectivos, como "los negros para la cultura norteamericana [en la que], un poco de 'sangre' africana ya los hace negros". ${ }^{39}$

Para nosotros, que ahora estamos interesados en la historia del pueblo gitano en Europa, fue emocionante descubrir que al tratar sobre el Holocausto y los peores efectos del antisemitismo, Gara dedicara un espacio a introducir el tema del genocidio romaní perpetrado por el nazismo. Es un espacio en apariencia pequeño (una bien documentada nota 40 en la página 105) pero en realidad enorme, pues no solo expresa una sensibilidad hacia el sufrimiento de otros grupos estigmatizados, sino que además constituye una excepción notable respecto al desconocimiento generalizado sobre el tema que hay en la profesión.

Sin duda, esta capacidad para extender la compasión y la demanda de justicia a colectivos sociales ajenos a los sentidos como propios -esa capacidad en definitiva para hacer porosas y transitables las fronteras de las identidades colectivas- tiene su mayor asiento en esa disposición intelectual (y emocional) a reconocer al "otro" de la que venimos hablando. Estas memorias nos devuelven a un Juan Carlos frecuentemente dispuesto a valorar otras racionalidades, como señaladamente recoge el recuerdo de una curandera a la que unos compañeros recurrieron -con éxito- dada la enfermedad sin aparente solución de su hija. El joven Gara fue capaz de reconocer que en ese momento aprendió mucho "acerca del debido respeto a otras formas de encarar la curación y la vida en general"; e, incluso, extiende el reconocimiento debido a los "otros" a momentos posteriores de madurez, como en el doctorado de la EHESS, cuando sintió que su pasado le ayudaba para "evitar acudir a racionalidades abusivas" a la hora de interpretar fenómenos culturales ajenos a la lógica de la modernidad occidental. ${ }^{40}$

Este conjunto de actitudes que hemos venido agrupando en las ideas de pluralismo cultural y tolerancia intelectual conforman un bagaje complejo. Por ello, es difícil calificar a Juan Carlos, resolver su adscripción -ya sea historiográfica, ya sea cultural- con unas cuantas etiquetas. Rendido admirador de Francia como símbolo y como modelo académico, "mi querida segunda patria", no deja de criticar duramente sus traiciones a los derechos humanos cuando tiene que hacerlo (como al hablar del terrorismo de Estado ${ }^{41}$ ). Como descendiente de una familia judía, tampoco le duelen prendas a la hora de criticar las políticas militaristas del Estado de Israel y la violencia aplicada contra los palestinos, momento en que su capacidad para reconocer los derechos del que está enfrente le muestra de nuevo al borde de la utopía:

“Lo asombroso (y que deja poco lugar para el optimismo acerca del comportamiento de las sociedades humanas) es que los descendientes del Holocausto puedan ser tan crueles con los pueblos vecinos a los que están despojando de sus tierras ancestrales. La paradoja que enfrenta a los judíos de la diáspora respecto a estas cuestiones es que, no siendo ciudadanos israelíes $\mathrm{y}$, por lo tanto, no pudiendo tener ningún peso sobre el accionar del Estado de Israel, se les pide que sean solidarios con

\footnotetext{
${ }^{39}$ GARAVAGLIA, Juan Carlos Una juventud..., cit., p. 106.

${ }^{40}$ GARAVAGLIA, Juan Carlos Una juventud..., cit., p. 176.

${ }^{41}$ GARAVAGLIA, Juan Carlos Una juventud..., cit., p. 205.
} 
sus acciones, lo que es sencillamente absurdo (nuevamente aquí aparece el peso de la "sangre"). La solución es conocida desde hace tiempo, dos estados independientes contiguos, con una ciudad, Jerusalén, repartida entre las tres religiones. Pero eso es soñar despierto." 42

Por otra parte, a pesar de que su herencia judaica venía acompañada de un notable escepticismo religioso, es capaz de reconocer que una experiencia espiritual intensa le estremeció profundamente al visitar la sinagoga portuguesa de Ámsterdam ${ }^{43}$-aquí no estás solo, Juan Carlos, otros agnósticos de otras tradiciones nos hemos sumergido sorprendidos como tú en la densidad espiritual de ese lugar inigualable.

En el fondo, nos parece que la vida de Juan Carlos Garavaglia estuvo marcada por una tensión enormemente productiva: su inclinación y su capacidad para la errance, por un lado, y su innata habilidad para el arraigo. Pudo -y necesitó- moverse, y a la vez supo -quiso- quedarse. Por ello, realmente vivió en todos los sitios en los que habitó: Buenos Aires, Madrid, México, París, Barcelona, Argelès-sur-Mer, Rosario... En temporadas de mucho viaje, como él mismo cuenta, era el canto de los pájaros -que empezó a conocer desde niño- lo que le permitía saber al despertarse "de qué lado del charco estoy". ${ }^{44}$ Esos pájaros, que a la vez marcan diferencias y comunican, pueden ser un buen símbolo de una vida que disfrutó de -nuevamente son sus palabras"mis dos mundos". Pero, por qué elegir nosotros símbolos, si Gara mismo lo hace al emplear como entrada del capítulo final de su libro unos versos que Lope de Vega dedicó al amor, y que el escritor de Una juventud en los años sesenta aplica al sentimiento de pertenencia:

Ir y quedarse y con quedar partirse

partir sin alma e ir con alma ajena...

Madrid y Sevilla, diciembre de 2017.

\footnotetext{
${ }^{42}$ GARAVAGLIA, Juan Carlos Una juventud..., cit., pp. 105-106.

${ }^{43}$ GARAVAGLIA, Juan Carlos Una juventud..., cit., p. 106.

${ }^{44}$ GARAVAGLIA, Juan Carlos Una juventud..., cit., p. 111.
} 